4 norden 



\section{BAT and Cleaner Technology in Environmental Permits}

Part 1: Summary, Analysis and Conclusion

PlanMiljø AS

TemaNord 2009:584 
BAT and Cleaner technology in Environmental Permits

Part 1: Summary, Analysis and Conclusion

TemaNord 2009:584

(C) Nordic Council of Ministers, Copenhagen 2009

ISBN 978-92-893-1946-1

Print: Kailow Express ApS

Printed on environmentally friendly paper

This publication can be ordered on www.norden.org/order. Other Nordic publications are available at www.norden.org/publications

Printed in Denmark

Nordic Council of Ministers

Store Strandstræde 18

DK-1255 Copenhagen K

Phone (+45) 33960200

Fax (+45) 33960202

Www.norden.org

\section{Nordic Council}

Store Strandstræde 18

DK-1255 Copenhagen K

Phone (+45) 33960400

Fax (+45) 33111870

\section{Nordic co-operation}

Nordic cooperation is one of the world's most extensive forms of regional collaboration, involving Denmark, Finland, Iceland, Norway, Sweden, and three autonomous areas: the Faroe Islands, Greenland, and Åland.

Nordic cooperation has firm traditions in politics, the economy, and culture. It plays an important rol in European and international collaboration, and aims at creating a strong Nordic community in a strong Europe.

Nordic cooperation seeks to safeguard Nordic and regional interests and principles in the global community. Common Nordic values help the region solidify its position as one of the world's most innovative and competitive. 


\section{Content}

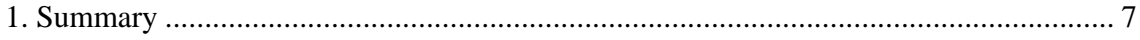

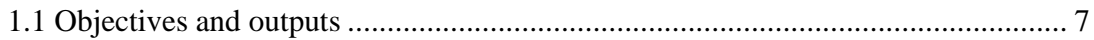

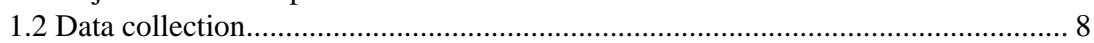

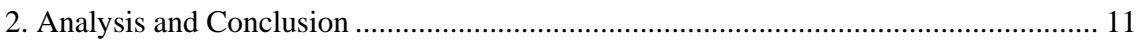

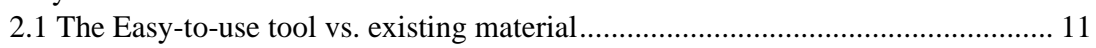

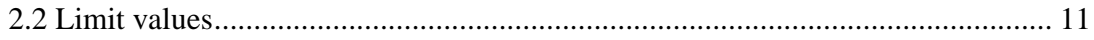

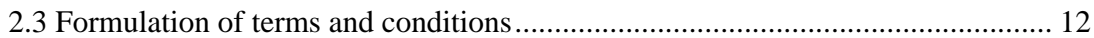

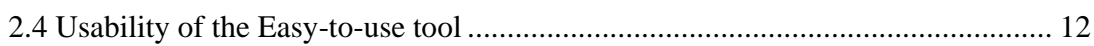

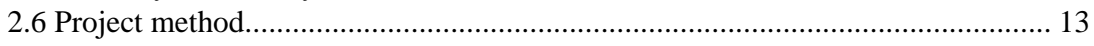





\section{Summary}

The working committee Product/Waste (The P/A group) under the Nordic Council has asked PlanMiljø to prepare a pilot-sample of an Easy-to-use tool identifying terms and requirements for Best Available Technology (BAT) and Cleaner Technology (CT) in environmental permits in the Nordic countries. The project has concentrated its resources within the industrial sectors of fish processing and surface treatment of metals.

Investigations on relevant permit requirements have been carried out in Denmark, Iceland, Norway and Sweden.

This document contains the summary of findings, analysis and conclusion of the project. The Easy-to-use tools for the two industrial sectors are attached in two independent documents:

- BAT and Cleaner Technology in Environmental Permits in the Nordic Fish Processing Industry

- BAT and Cleaner Technology in Environmental Permits in the Nordic sector of Surface Treatment of Metals.

The specific target groups for the Easy-to-use tools are:

- Primarily permitting staff working in environmental authorities in smaller communities

- Staff with environmental tasks in small and medium sized enterprises (SMEs) in the two sectors.

\subsection{Objectives and outputs}

The immediate objective of the project has been to generate an Easy-touse tool for Nordic environmental authorities providing them with guidance. More specifically, what terms can be used when formulating BAT and CT conditions in the permit and licensing process. The tool can also be seen as a guide to industries applying for permits.

The main outputs have been:

- An overview of BAT and CT information from Nordic and international documents;

- An overview of practices used by Nordic permit writers in terms of BAT and CT requirements;

- An overview of the Nordic experience concerning BAT and CT requirements in environmental permits. 
The BAT and CT requirements identified are in the Ease-to-use tools separated into various themes to ease the user's identification of relevant information. The tools can easily be transformed into an internet tool if found relevant.

\subsection{Data collection}

The data collection has focused on acquiring relevant environmental permits from environmental authorities in the Nordic countries. It was carried out with support from local environmental officers. The following numbers of permits have been acquired:

- Surface treatment of metals: 37 environmental permits have been compiled and reviewed, hereof six from Sweden, two from Norway and 29 from Denmark

- Fish processing industry: 35 permits have been compiled and reviewed, including 18 from Sweden, eight from Norway, two from Iceland, three from the Faroe Islands, and four from Denmark.

The number of permits compiled does not fully live up to the expected, illustrating the challenge of basing the project on input from busy staff from environmental authorities in a long term project with sequential involvement.

\subsubsection{Selection of relevant information from the permits}

All permits have been reviewed in their entity and relevant information derived preferably in the original form. The following criteria have been used for selecting relevant conditions and passages from the permits:

- The review has aimed at identifying terms specifically targeting BAT and CT in terms of techniques, operational requirements or other relevant formulations

- Terms relevant for SMEs have been prioritised

- Terms of non-specific, "soft" nature have been excluded (e.g. "it is a good idea to...”)

- Terms not going beyond national legislation have been excluded (as these can be found by referring to the relevant authorities)

- Terms concerning noise or heating of the premises have not been included. 


\section{Surface treatment of metals}

The project has looked specifically into the following seven surface treatment processes being known as the most common methods in the sector:

- Blast cleaning

- Degreasing with organic solvents

- Water based degreasing

- Galvanising

- Powder painting

- Spray painting with liquid organic coatings

- Immerse finishing

The main environmental impacts from these processes are:

- Blasting processes: dust.

- Degreasing with organics solvents: emission of solvents into the air.

- Water based degreasing: oil in waste water and heavy metals.

- Galvanising: the release of aerosols that influence the working environment.

- Powder painting: emission of dust,

- Spray painting: emission of vaporised organic solvents.

- Immerse finishing: emission of solvents.

- Furthermore, the processes all create hazardous waste.

Fish processing industry

The fish processing industry covers a huge variety of different productions technologies and products - to a large degree with similar environmental discharges. For a list of the most common processing techniques applied, please refer to the fish processing industry report.

The main environmental impacts for the fish processing industry are:

- High water consumption.

- Large amount of waste waster with high levels of organic substances and remains from cleaning substances.

- High energy consumption for certain processes.

- Odour from bad handling and storage of waste and by-products and from smoke processing. 



\section{Analysis and Conclusion}

\subsection{The Easy-to-use tool vs. existing material}

There exist different types of relevant material in the area of BAT and CT within the two industrial sectors.

The primary material is the BREF documents, voluminous, detailed, and excellent when identifying potentials for improvement in larger enterprises. The BREFs include benchmarking figures that describe the emission of various pollutants from various processes. However, the BREF documents do not directly provide input to environmental conditions in permits, especially not for SMEs, and technology descriptions can not be used directly by a local authority. Moreover, the BREFs are not that easy accessible due to their complexity and considerable size.

Several documents have been produced in the Nordic countries to challenge the complexity of the BREFs and to provide more accessible input for environmental optimisation of the Nordic SME's. These documents are easier to access for SME's and regulators but do not state actual terms and conditions to be used in the environmental permits.

The Easy-to-use-tools produced in this project are more applicable as they include formulations directly quoted from existing permits and easily adopted in new permits. The difference between the Easy-to-use-tool and other documents dealing with BAT/CT is at the level of application.

\subsection{Limit values}

One of the aims of the project has been to provide the Nordic authorities an overview of the limit values used in the Nordic countries as inspiration for defining local limit values.

Specific emission limit values have only been found to a limited extent. In general, emission limit values in the environmental permits refer to national legislation or limits stated in national guidelines. Hence, authorities seldom introduce limit values diverging from the national limit values - reportedly for three reasons:

- Using national guidelines or legally determined limit values reduce the risk of legal problems and complaints by the enterprises.

- It is acknowledged that the competent national authorities have the best understanding of the cost and benefits of various limit values. Using national defined limit values ensures agreement between the national environmental goals and the local environmental efforts. 
- If all enterprises have the same limit values, decided at a national level, the risk of unfair competition, due to different environmental terms, is avoided.

If there are no national emission limit values, the limit values from other countries can be an inspiration. These can be found by contacting the appropriate authority.

\subsection{Formulation of terms and conditions}

In general, the terms and conditions are formulated in relation to national legislation and guidelines, but the formulation and set up of the permit differ greatly from authority to authority. The more recent permits appear more standardised also between municipal environmental units, likely illustrating national efforts of harmonising the contents and appearance of environmental permits. Most environmental permits focus on the total emission to avoid that environmental problems are solved by dilution.

It is worth noticing that the Easy-to-use tools to a very high degree directly quote the formulations from the original permits. This has been a deliberate choice. There has been made no attempt or effort to change the text, and the concordance with national legislation or BREFs have not been tested. The tools, thus, do not pretend to present universal formulations that are legally acceptable in all situations - they simply present an historic overview of the work carried out by permitting officers.

Obviously, the text should not be copied directly without considering the context in which it is to be used.

\subsection{Usability of the Easy-to-use tool}

The need for making Easy to-use tools was identified by the members of the P/A group and has been confirmed through the projects' many contacts with local permitting officers, not least in smaller communities. The tools can be used as inspiration in the licensing process in so far they correspond with the valid national legislation. Hopefully this can to a certain degree ease the work with preparing environmental permits that include preventive measures as BAT and CT.

In this context it is important to bear in mind that formulating terms and conditions is only a part of the environmental permitting process. Other important elements of the process are establishing and maintaining a constructive and prevention oriented dialogue with the representative of the enterprises and guiding them to sources of relevant information. 
If the Easy-to-use tools are to be used they obviously have to be available and known by the potential users. How to handle this aspect is up to the P/A group to decide on.

The tools are produced in a form that makes it relatively easy to transform them into an internet tool.

\subsection{Project method}

It can be relevant to analyse the method used for collecting the environmental permits as this turned out to be a weak point in the project set-up.

Establishing contacts with relevant local permitting officers in the different countries was a very long process. After more than one year's contact to national and local environmental focal points, finally the project could benefit from a competent and engaged working group.

The concept of conveying the responsibility for compiling relevant environmental permits to local environmental experts appears obvious as the experts can draw on their professional networks and expertise within the selected industrial sectors. In the project proposal it was also foreseen that the working group members would derive the relevant passages and formulations from the compiled permits and also engage in discussions on the relevance and adequacy of the identified permit passages from all participating countries.

It must though be concluded that the number of working group meetings planned for (and budgeted) did not cater for the need for personal cooperation and participation in the rather elongated project. Both establishment of the working group and the practical compilation of the needed environmental permits turned out to be more difficult than expected, and the number of permits acquired form the participating countries does not fully live up to the expected. The practical review of the permits compiled has by and large been conducted by the consultant.

The communication with the working group has throughout the project been positive and constructive, and the working group members have provided valuable insight, comments and recommendations to the project all the way through.

Conclusively, if similar projects are to be carried out it can be recommended:

- to form the working group immediately after project take off with the engaged support of the national environmental authorities;

- to carry out the project in a concentrated and dynamic process over a limited time span;

- to more realistically divide the work tasks among working group members and consultants, acknowledging the existing and extensive work load on the local environmental experts. 